\title{
On the effect of drag forces in mooring system restoring forces
}

\author{
Zahid Ullah ${ }^{1}$, Naik Muhammad ${ }^{1}$, Ji-Hoon Lim $^{1}$, and Dong-Ho Choi ${ }^{2, *}$ \\ ${ }^{1} \mathrm{Ph} . \mathrm{D}$. Candidate, Department of Civil and Environmental Engineering, Hanyang University \\ 222, Wangsimni-ro, Seongdong-gu, Seoul, 04763, Republic of Korea \\ ${ }^{2}$ Professor, Department of Civil and Environmental Engineering, Hanyang University \\ 222, Wangsimni-ro, Seongdong-gu, Seoul, 04763, Republic of Korea
}

\begin{abstract}
Mooring line is a major source of stability and plays a key role in the global response of offshore floating wind turbine. In the current state of the research, a formulation based on the analytical catenary equation is most commonly used for the analysis of mooring lines. However, due to the inability of catenary equations to consider the ocean current drag forces on mooring lines, the effect of drag forces on fairlead restoring forces has not been investigated yet. In this study, we have investigated the influence of drag forces on fairlead forces using discrete catenary formulation for modeling mooring line. The discrete catenary formulation has the ability to incorporate ocean current drag forces. Three types of elements; fully suspended, touchdown and seabed element are formulated to model the suspended, touchdown and seabed portion of a slack mooring line, respectively. The influence of viscous drag on the fairlead restoring forces is demonstrated through the analysis of OC3-Hywind mooring system subjected to ocean currents. It was found that the viscous drag significantly influences the fairlead forces.
\end{abstract}

\section{Introduction}

The increasing demand for exploitation of renewable wind energy has dramatically increased the size of the offshore floating wind turbine and pushed the installation of floating wind turbine away from shore in the deeper water. This development of offshore floating wind turbine has resulted in the need for more accurate analysis and simulation tools. Mooring line plays an important role in the stability and the global response of the floating wind turbine. The accurate prediction of mooring loads and fairlead forces is necessary for the safe design of floating wind turbine. Various numerical models have been proposed by various researchers for the analysis of mooring lines. The finite element method has been widely used for analysis of mooring lines [1-2]. However, the high computational cost is a major weakness of the finite element modeling. Due to computational efficiency and easier implementation, the analytical catenary approach has been widely adopted by the various researcher [3-4] for the analysis of mooring lines. However, it is incapable of taking into account the ocean current drag forces. Therefore, the

\footnotetext{
* Corresponding author: samga@hanyang.ac.kr
} 
effect of ocean current drag forces on the fairlead forces has not been studied. The present is study focused on the influence of drag forces on the mooring line restoring forces.

\section{Mathematical formulation of mooring line}

An improved quasi-static model based on the discrete catenary formulation is used for the analysis of mooring lines. To model the suspended, touchdown and seabed portion of a slack mooring line three types of discrete catenary elements; suspended, touchdown and seabed are used, respectively, as shown in Fig. 1. The drag forces in vertical and horizontal directions are denoted by $f_{x}$ and $f_{y}$, respectively; $F_{1}$ and $F_{2}$ denotes the fairlead restoring forces in horizontal and vertical directions, respectively; $L_{x}$ and $L_{y}$ represents the horizontal and vertical projections of the mooring line, respectively, and $w$ is the unit selfweight of the mooring line.

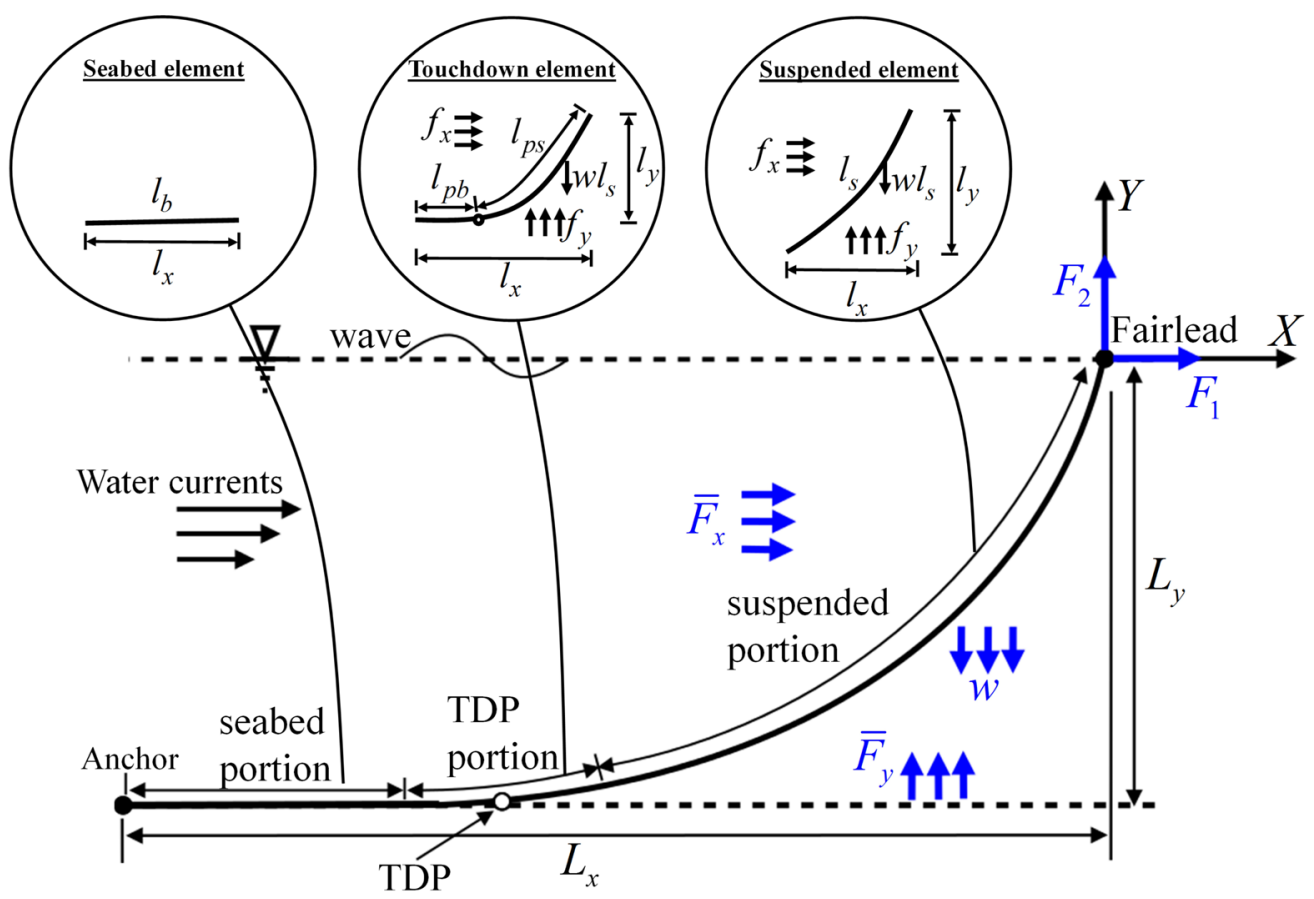

Fig. 1. Mooring line layout and discrete catenary cable elements.

\subsection{Suspended element}

The suspended portion of mooring line is modeled using suspended element. The horizontal and vertical projection of a suspended element $(i=n-1)$ can be determined as:

$$
l_{x}=-\frac{\left(F_{1}+\bar{F}_{x}\right) l_{s}}{E A}-\frac{\left(F_{1}+\bar{F}_{x}\right) l_{s}}{\sqrt{\left(F_{1}+\bar{F}_{x}\right)^{2}+\left(-F_{2}+\bar{F}_{y}\right)^{2}}}
$$




$$
l_{y}=\frac{\left(-F_{2}+\bar{F}_{y}\right) l_{s}}{E A}+\frac{\left(-F_{2}+\bar{F}_{y}\right) l_{s}}{\sqrt{\left(F_{1}+\bar{F}_{x}\right)^{2}+\left(-F_{2}+\bar{F}_{y}\right)^{2}}}
$$

where the $l_{s}$ represent the unstrained length of the element; $\bar{F}_{x}=\sum_{i=1}^{n-1} f_{x}^{i} l_{s}^{i}$ and $\bar{F}_{z}=\left((n-1) w-\sum_{i=1}^{n-1} f_{z}^{i}\right) l_{s}^{i}$ are the drag forces on the element in horizontal and vertical directions, respectively and $i$ represent element number $(i=1$ to $N)$.

\subsection{Touchdown element}

The touchdown portion of mooring line is modeled using a touchdown element. The touchdown element is partially suspended and partially laying on the seabed. The suspended portion of touchdown element is denoted by $l_{p s}$, and the seabed portion of touchdown element is denoted by $l_{p b}$. The horizontal and vertical projections of the touchdown element $(i=n)$ can be determined as follow:

$$
\begin{aligned}
& l_{x}=-\frac{\left(F_{1}+\bar{F}_{x}+f_{x}^{n} l_{p s}\right)\left(l_{p s}+l_{p b}\right)}{E A}-\frac{\left(F_{1}+\bar{F}_{x}+f_{x}^{n} l_{p s}\right)\left(l_{p s}+l_{p b}\right)}{\sqrt{\left(F_{1}+\bar{F}_{x}+f_{x}^{n} l_{p s}\right)^{2}+\left(-F_{2}+\bar{F}_{y}+\left(w-f_{y}^{n}\right) l_{p s}\right)^{2}}} \\
& l_{y}=\frac{\left(-F_{2}+\bar{F}_{y}+\left(w-f_{y}^{n}\right) l_{p s}\right) l_{p s}}{E A}+\frac{\left(-F_{2}+\bar{F}_{y}+\left(w-f_{y}^{n}\right) l_{p s}\right) l_{p s}}{\sqrt{\left(F_{1}+\bar{F}_{x}+f_{x}^{n} l_{p s}\right)^{2}+\left(-F_{2}+\bar{F}_{y}+\left(w-f_{y}^{n}\right) l_{p s}\right)^{2}}}
\end{aligned}
$$

\subsection{Seabed element}

In the slack configuration of mooring line, a significant portion of mooring line is lying on the seabed. The seabed portion of mooring line is modeled using seabed elements. The unstrained length of a seabed element is denoted by $l_{b}$. The projections of a seabed element $(i=n+1)$ can be determined as follows:

$$
\begin{gathered}
l_{x}=-\left(1+\frac{\left(F_{1}+\bar{F}_{x}+f_{x}^{n} l_{p s}\right)}{E A}\right) l_{b} \\
l_{y}=0
\end{gathered}
$$




\section{Results and discussions}

The influence of drag forces on restoring forces is investigated through the analysis of OC3-Hywind [5] mooring system subjected to an ocean current. The mooring system consists of three mooring lines. The diameter of a mooring line is $0.09 \mathrm{~m}$, mooring line weight in water is $698.094 \mathrm{~N} / \mathrm{m}$, and the angle between adjacent mooring lines is $120^{\circ}$. Further details are given in Table 1.

Table 1. OC3-Hywind mooring system properties.

\begin{tabular}{|c|c|}
\hline Parameter & Value \\
\hline Depth to fairlead from mean sea level & $70 \mathrm{~m}$ \\
\hline Depth to anchor from mean sea level & $320 \mathrm{~m}$ \\
\hline Radius to fairlead from center line of platform & $5.2 \mathrm{~m}$ \\
\hline Radius to anchor from center line of platform & $853.87 \mathrm{~m}$ \\
\hline Axial stiffness of mooring line & $384243000 \mathrm{~N}$ \\
\hline
\end{tabular}

The OC3-Hywind mooring system is subjected to ocean current of velocity $2.5 \mathrm{~m} / \mathrm{s}$. The angle $\theta$ represents the direction of ocean current with the respect to x-axis. The floating platform is quasi-statically displaced from $-24 \mathrm{~m}$ to $+24 \mathrm{~m}$ in a sway direction. The influence of drag forces on the surge, sway and heave restoring forces is demonstrated in Fig. 2 (a-c) for current velocities $V=0,2.5 \mathrm{~m} / \mathrm{s}$, and $\theta=0^{\circ}, 45^{\circ}$. The figure shows that drag forces significantly influence the fairlead forces. The effect of drag forces on the surge and heave restoring forces is more pronounced. The effect of sway restoring forces is insignificant for $\theta=0^{\circ}$, however, the effect is increased for $\theta=45^{\circ}$. The comparison of results also demonstrates that the net effect of drag forces on total restoring forces depends on the direction of ocean current with respect to the orientation of the mooring lines. For example, the effect of drag forces on heave restoring is insignificant for $\theta=0^{\circ}$, But for $\theta=$ $45^{\circ}$ the influence of drag forces on heave restoring forces increased profoundly.
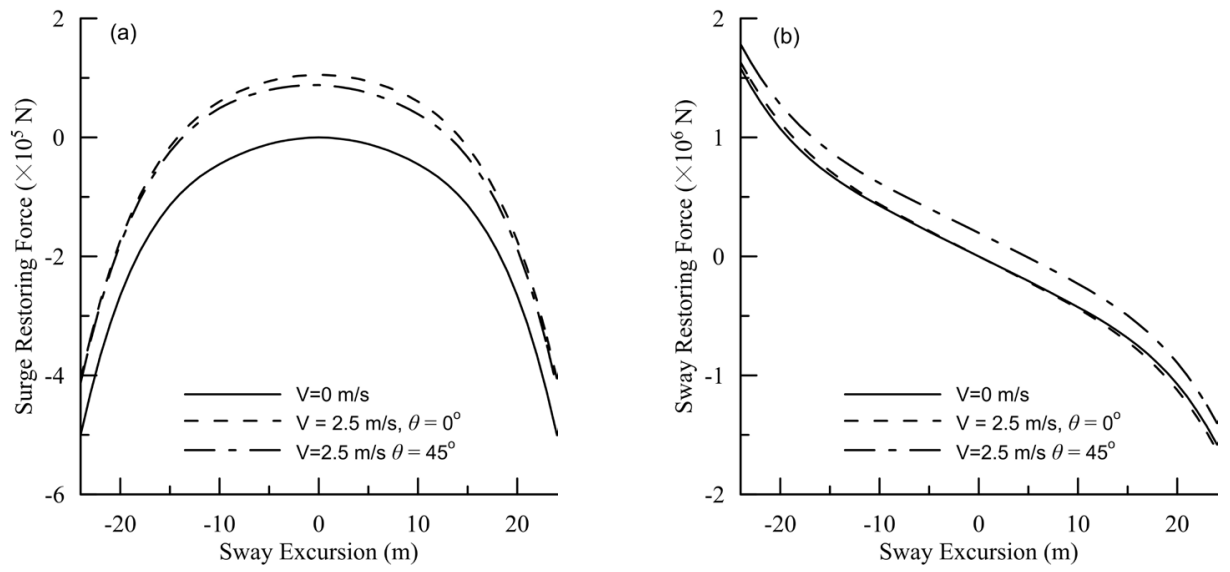


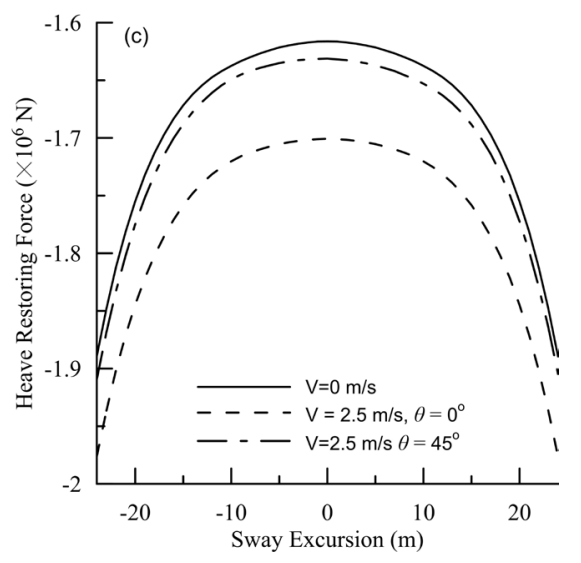

Fig. 2. Restoring forces vs sway displacement (a) surge restoring force, (b) sway restoring force, and (c) heave restoring force.

\section{Conclusions}

This study investigated the effect of ocean current drag forces on mooring system restoring forces. The mooring system restoring forces play a key role in the stability of floating wind turbine. Mooring lines are modeled using discrete catenary cable element. The effect of drag forces on mooring system restoring forces is investigated through the analysis of OC3Hywind mooring system. It was found that the drag forces significantly influence the mooring system restoring forces. The effect of viscous drag forces in a specific direction i.e. surge, sway and heave depends on the direction of ocean currents with respect to mooring lines.

This research was supported by the Basic Science Research Program through the National Research Foundation of Korea (NRF), funded by the Ministry of Education, Science and Technology (NRF2015R1D1A1A09060113). The authors wish to express their gratitude for this financial support.

\section{References}

1. N. Haritos, D. He, Modelling the response of cable elements in an ocean environment, Finite elements in analysis and design, 11, 19-32, (1992)

2. Z. Ran, M. Kim, Nonlinear coupled responses of a tethered spar platform in waves. International Journal of Offshore and Polar Engineering, 7, 111-118, (1997)

3. R.P. Singh, J. Verma, Evaluation of force-displacement relationship for multicomponent mooring cable by F.E.M., Computers \& Structures, 30, 1079-1089, (1988)

4. JM. Jonkman, Dynamics modeling and loads analysis of an offshore floating wind turbine, ProQuest; (2007)

5. JM. Jonkman, Definition of the floating system for phase IV of OC3, National Renewable Energy Laboratory Golden, CO, USA, (2010) 